\title{
Cancer Treatment with Per Os Administered Methotrexate
}

\author{
Kazuo Maeda \\ Department of Obstetrics and Gynecology, Tottori University Medical \\ School, Yonago, Japan
}

\author{
${ }^{*}$ Corresponding author \\ Kazuo Maeda, Department of Obstetrics and Gynecology, Tottori University \\ Medical School, Yonago, Japan \\ Submitted: 05 Jan 2021; Accepted: 12 Jan 2021; Published: 18 Jan 2021
}

citation: Kazuo Maeda (2021) Cancer Treatment with Per Os Administered Methotrexate. Medical \& Clinical Research 6(2): 403.

As new anticancer agents are tried cancer treatment, the author remembered complete remission of choriocarcinoma and metastases with methotrexate (MTX) administered within some months, to get normal uterine pregnancy and usual life, thus wondered non-sergical MTX treatment of human common cancer, and several cancer treatments in Pubmed and NIH reports with success. The amount of chorioarcinoma therapy by MTX was 0.45 $\mathrm{mg} / \mathrm{kg} /$ day, 200mg in a week, inserting some days' rest, and repeated some months to get the full necrosis of uterine primary focus and metastases in my complete remission. Side effect was leuopenia, liver and kidney damage, gastric damage, etc, treated with interval of MTX, bone marrow injection, leucopeia drugs and folic acid injection [1]. Not only trophoblastic tumour, but MTX was effective by metabolic damage of cancer cells, where any damaging cancer effect is expected. As uterine cervical cancer is easily observed by colposcopy and easily punch cancer tissue, it is thought to be suitable subject of MTX therapy. Authors experience was infusion of MTX into uterine artery which was effective to reduce the volume of cervical choriocarcinoma. In gastric cancer, for example, the cancer will be observed by endoscopy and cancer tissue sampling to observe the MTX effect without gastrectomy, there will be no pain in the MTX therapy instead of stomach rejection. Any cancer is treated without pain of surgery.

\section{References}

1. Maeda K, YoMshioka S, Iba N (1970) Treatment of choriocarcinoma. Jpn Obstetrics and Gynecology 20: 483484.
Copyright: (02021 Kazuo Maeda. This is an open-access article distributed under the terms of the Creative Commons Attribution License, which permits unrestricted use, distribution, and reproduction in any medium, provided the original author and source are credited. 